\title{
A Study in Mauve: Unveiling Perkin's Dye in Historic Samples
}

\author{
Micaela M. Sousa, ${ }^{[a]}$ Maria J. Melo, ${ }^{*[a]}$ A. Jorge Parola, ${ }^{[b]}$ Peter J. T. Morris, ${ }^{[c]}$ \\ Henry S. Rzepa, ${ }^{[d]}$ and J. Sérgio Seixas de Melo*[e]
}

\begin{abstract}
The analysis of different historic mauve samples-mauve salts and dyed textiles-was undertaken to establish the exact nature of the iconic dye produced by W. H. Perkin in the nineteenth century. Fourteen samples from important museum collections were analyzed, and it was determined that, in contrast to the general wisdom that mauveine consists of $\mathrm{C}_{26}$ and $\mathrm{C}_{27}$ structures, Perkin's mauveine is a com-
\end{abstract}

plex mixture of at least thirteen methyl derivatives $\left(\mathrm{C}_{24}\right.$ to $\left.\mathrm{C}_{28}\right)$ with a 7-amino5-phenyl-3-(phenylamino)phenazin-5ium core. A fingerprint was established in which mauveines $\mathrm{A}$ or B were dominant, and in which mauveines B2 and

Keywords: chemical archaeology • dyes/pigments $\cdot$ mauveine $\cdot$ Perkin . structure elucidation
$\mathrm{C}_{25}$ were found to be important tracers to probe the original synthesis. Counterion analysis showed that all the mauve salts should be dated after 1862 . Perkin's original recipe could be identified in three textile samples, and in these cases, mauveines $\mathrm{A}$ and $\mathrm{C}_{25}$ were found to be the major chromophores. These are now shown to be the samples containing the "original mauve".

\section{Introduction}

Mauveine in a historical context: The synthetic colourant mauveine is a major landmark in the history of science and technology, which led to the emergence of the synthetic dye industry. The synthesis of mauveine-variously known as aniline purple (1857), Tyrian purple (1858), mauve dye

[a] M. M. Sousa, Dr. M. J. Melo

Departamento de Conservação e Restauro and REQUIMTE, CQFB Faculdade de Ciências e Tecnologia/UNL

2829-516 Caparica (Portugal)

Fax: $(+351) 212948322$

E-mail: mjm@dq.fct.unl.pt

[b] Dr. A. J. Parola REQUIMTE, CQFB

Departamento de Química, Faculdade de Ciências e Tecnologia/UNL 2829-516 Caparica (Portugal) Fax: $(+351) 212948055$

[c] Dr. P. J. T. Morris

The Science Museum, London SW7 2DD (UK)

[d] Prof. Dr. H. S. Rzepa

Department of Chemistry, Imperial College London SW7 2AZ (UK)

[e] Dr. J. S. S. de Melo

Department of Chemistry, University of Coimbra 3004-535 Coimbra (Portugal)

Fax: $(+351) 239827703$

E-mail: sseixas@ci.uc.pt

Supporting information for this article is available on the WWW under http://dx.doi.org/10.1002/chem.200800718. (from 1859), phenamine or indisine $\mathrm{e}^{[1]}$ - is a story that demonstrates how well-prepared minds can succeed, in this case with new colours, in contributing to an important period in the history of the modern world. The history of this discovery and of Perkin's life is well documented. ${ }^{[2-6]}$ However, perhaps the best account is that given by Perkin himself at the banquet in his honour in New York City (October 6, 1906) on the occasion of the Jubilee of his discovery, as well as his earlier research articles. ${ }^{[7,8]}$ The original mauve (Figure 1) is believed to have been synthesised by Perkin on 23 March 1856 and patented in 1856 (granted on 26 August 1856 and sealed on 20 February 1857). ${ }^{[6,9]}$ Mauve was manufactured on a small industrial scale at Greenford, Middlesex, by William Perkin, his father George Fowler Perkin and his brother Thomas Dix Perkin, between late 1857 and the end of $1873 .{ }^{[7]}$ As mentioned by Perkin himself "the mauve was supplied for silk dyeing as early as December 7 1857".[7] However, the commercial interest in mauve declined long before Perkin sold his factory (in 1873). Hence the production of mauveine (mauveine basic dye C.I.: 50245), and consequently the dates of the existing historical samples, covered the period between 1857 to around 1864 .

Mauve dye and mauveine salts were prepared by Perkin in the pursuit of three different objectives: to manufacture a product to be sold as a dye, to obtain a pure compound suitable for structure elucidation, and eventually, for patent protection. To be used as a textile dye, the chromophore should display a desirable colour; it should also be resistant to 


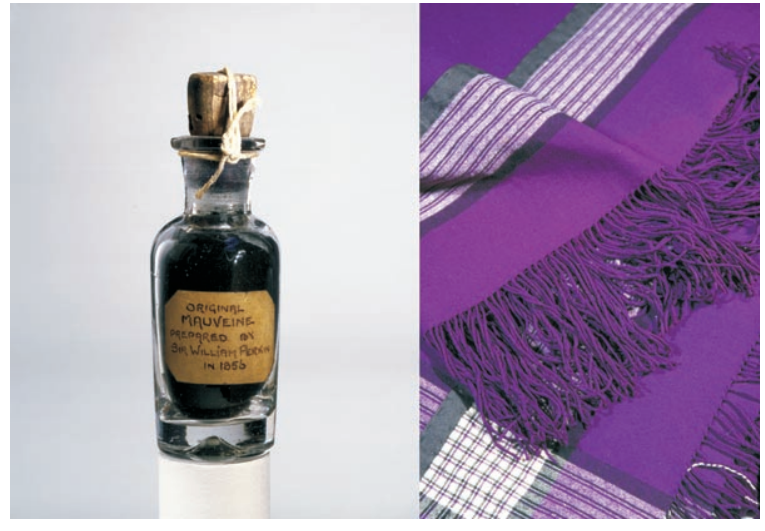

Figure 1. The Science Museum's “Original Sample” of mauve (left). In this work, it is shown that this sample was obtained by a second synthetic process developed by Perkin, and therefore it cannot be considered to be the result of Perkin's pioneer synthesis. The result of the original process of 1856-7 may still exist in three textile samples; the shawl shown on the right, corresponding to the analysed Science Museum F6 fabric, is one of these samples, see text. Figure reproduced with permission from the Science Museum, London.

light-induced and pollution-induced fading and to washing. Mauve, as a successful dye, fulfilled all these criteria.

Perkin's mauve: It is important to examine some of Perkin's own results, as they are of relevance to the understanding of our results, namely, to the pioneering analysis of the historic fabrics that will be discussed in this paper. Relevant data from Perkin's publications are the empirical formula for mauveine, which was defined by him as the base of mauve, $\mathrm{C}_{27} \mathrm{H}_{24} \mathrm{~N}_{4}$, and that was communicated in August 19, 1863. This formula was further confirmed in Perkin's ${ }^{[10]} 1879$ paper, one of a series dedicated to research in mauve chemistry. ${ }^{1}$ In between these two communications, Perkin had assigned a $\mathrm{C}_{26}$ structure for mauveine. ${ }^{[10] 2}$ In the 1879 paper, we also learn about the postulated formula for pseudo-mauveine, $\mathrm{C}_{24} \mathrm{H}_{20} \mathrm{~N}_{4}$, considered by Perkin as "the second colouring matter in the mauve dye". ${ }^{[10]}$ Indeed in his last published contribution to the chemical elucidation of mauveine, his memorial lecture for Hofmann, Perkin asserted that mauveine was a mixture of pseudo-mauveine $\left(\mathrm{C}_{24}\right)$ and of a trimethylated homologue $\left(\mathrm{C}_{27}\right) \cdot{ }^{[8]}$ Also, and most importantly, in Perkin's contributions, details were given concerning the manufacture of the mauve dye. He explained that he used at least two methods for the production of the commercial mauve dye that afforded: "two different products, namely, a blue shade of mauve prepared from aniline, containing little toluidine, and a red shade from an aniline containing large quantities of toluidine". Mauve was first sold as an "amorphous body", in the form of the sulfate salt.

${ }^{1}$ Quote from Perkin (see reference [10], p. 720): "These results therefore confirm the original formula, $\mathrm{C}_{27} \mathrm{H}_{24} \mathrm{~N}_{4}$ ".

${ }^{2}$ Quote from Perkin (see reference [10], p. 718): "After the publication of my paper on Mauve or Aniline Purple, I was induced to modify the formula of mauveine, and to regard it as containing C26 instead of C27".
After this first process, the mauve dye was then manufactured in a second optimised process and sold as the acetate salt of mauveine. This happened because the first salt, the mauveine sulfate, obtained from the synthesis during the purification was not soluble enough to be used as a dye; as Perkin stated it was "unsuitable for the dyer". ${ }^{[10]}$ To precipitate the mauveines as acetate salts, the process was modified, and large quantities of the starting material toluidine were used. ${ }^{[10]}$ As we know now, and as Perkin would have known in the late 1860 's, the aniline that he used when he discovered mauve was a mixture of aniline with both ortho and para-toluidine. ${ }^{[10] 3}$ It is worth mentioning that, the general synthetic procedure was already described by Perkin in $1862^{[1] 4}$ and that, in 1879 Perkin concludes that "Up to the present, very little is known of the constitution of mauveine, but there can be no doubt it is derived from aniline and paratoluidine." $[10]$

In conclusion, Perkin was able to determine a molecular formula but not a molecular structure (although he did speculate upon one). With Perkin the chemical formula for mauveine changed from $\mathrm{C}_{27}$ to $\mathrm{C}_{26}$ and then back again to a final $\mathrm{C}_{27}$.

What is mauve? Although the research on the molecular structure of mauve began with Perkin himself, ${ }^{5}$ it was resolved only in 1994, with the work of Meth-Cohn and Smith. ${ }^{[11]}$ Other attempts to determine its structure were made during the end of the 19th century, ${ }^{[12,13]}$ and in the 20th century. ${ }^{[14,15]}$ In their pioneering analysis of historic salt samples, obtained from the Science Museum (London) and from the then Zeneca archives at Blackley (Manchester) published by Otto Meth-Cohn and Mandy Smith in 1994, two compounds were considered to be the main chromophores, mauveine $\mathrm{A}$ (major compound) and $\mathrm{B}, \mathrm{C}_{26}$ and $\mathrm{C}_{27}$ structures, respectively, see Scheme $1 .{ }^{[11]}$ Later on, by using a modern synthesis, some of us verified ${ }^{[16]}$ that it was possible to obtain pseudo-mauveine $\left(\mathrm{C}_{24}\right)$, mono $\left(\mathrm{C}_{25}\right)$, di- $\left(\mathrm{C}_{26}\right)$, tri$\left(\mathrm{C}_{27}\right)$ and tetramethylated $\left(\mathrm{C}_{28}\right)$ derivatives by using aniline, $o$-toluidine and $p$-toluidine as starting materials, and depending on the ortho to para ratios, to also obtain different isomeric ratios. Two other compounds, mauveine B2 and $\mathrm{C}$, $\mathrm{C}_{27}$ and $\mathrm{C}_{28}$ compounds, respectively, were then discovered during analysis. ${ }^{[16]}$

\footnotetext{
3 This emerged from Hofmann's studies in the early 1860's (aniline and toluidine were both present in the reactants used for aniline red synthesis; see reference [22]) and from Rosenstiel's studies (see reference [23]) on the isomerism of nitrotoluenes (which suggested the presence of isomers of aniline red).

${ }^{4}$ Quote from Perkin (see reference [1], p. 233): "The method adopted for the preparation of aniline purple is as follows: solutions of equivalent proportions of sulphate of aniline and bichromate of potassium are mixed and allowed to stand till the reaction is complete."

5 While Perkin did not have the means to locate every atom in the molecule and thereby draw the complete molecular structure in modern terms, he could, from known properties of mauve, separate the molecule into groups of atoms, in other words, attempt to determine its constitutional formula.
} 


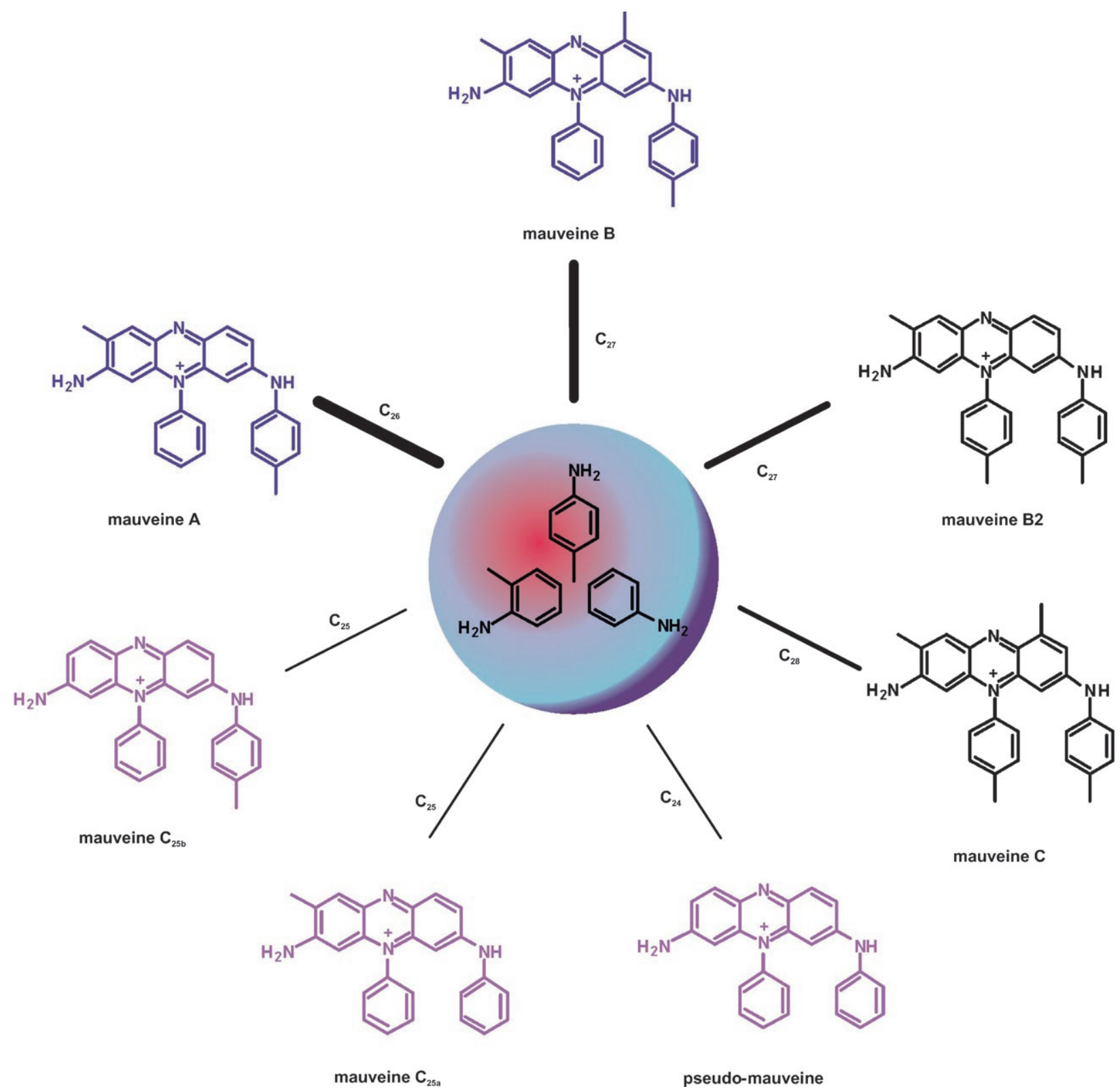

Scheme 1. Fully characterised products isolated from mauve samples. Depending on the initial ratio of aniline, $o$-toluidine and $p$-toluidine, the proportion of the different mauveine compounds varies. Mauveine A and B are the major components of all analysed mauveine salts but one, that from the Museum of Science and Industry of Manchester, in which pseudo-mauveine and mauveines $\mathrm{C}_{25_{2}}$ and $\mathrm{C}_{25}$ are predominant. Mauveine $\mathrm{B} 2$ and $\mathrm{C}$ are minor components. These seven compounds could be isolated in sufficient amounts to allow for MS and NMR spectroscopic characterization, whereas seven others could only be characterized by HPLC-MS. All thirteen compounds have wavelength absorption maxima in methanol in the range of 540 (mauveine E)-550 nm (mauveine B2), see Table S1 in the Supporting Information.

These data as well as the early data of Meth-Cohn and Smith ${ }^{[1]]}$ contradict Perkin's claim that the definite formula for industrial mauveine was a $\mathrm{C}_{27}$, mauveine $\mathrm{B}$ or an isomer, and that the second colouring matter was pseudo-mauveine. As it will be shown in this work, mauveine is a complex mixture and the conclusions of both the modern authors and Perkin have their merits.

\section{Results and Discussion}

\section{Analysis of Perkin's mauve in salt samples}

Chromophores: In this work, two sets of historical samples were analysed: seven mauve salts and seven dyed textiles, provided by the Science Museum (London), Museum of Science and Industry (Manchester), Chandler Museum (Columbia University) and Perth Museum (Scotland). The samples investigated here are dated from a period that ranges 
from 1857 to 1879 . An additional sample of mauve from Edward Schunck (also from the early days of mauve synthesis) was also analysed.

The samples were dissolved in methanol and analysed by HPLC-DAD and HPLC-DAD-MS. The major components were isolated and fully characterised by MS and NMR spectroscopy, in which minor components were only characterised by LCMS (see Tables S1-S6 and Figures S1-S5 in the Supporting Information for details). Scheme 1 shows the structures of the isolated compounds that could be fully characterised and Table 1 the distribution of the different chromophores amongst the historical samples.

Table 1. Relative percentages of the main chromophores of the mauveine salt samples ${ }^{[\mathrm{a}]}$ and respective counterions (A-acetate, $\mathrm{S}$-sulfate).

\begin{tabular}{llcllllllll}
\hline & $\mathrm{C}_{24}$ & $\mathrm{C}_{25}$ & $\mathrm{C}_{26}$ & $\mathrm{C}_{27}$ & $\mathrm{C}_{27}$ & $\mathrm{C}_{27}$ & $\mathrm{C}_{28}$ & $\mathrm{C}_{28}$ & $\begin{array}{l}\mathrm{C}_{26} / \\
\mathrm{C}_{27}{ }^{[\mathrm{b}]}\end{array}$ & $\begin{array}{l}\text { Anion } \\
{[\%]}\end{array}$ \\
& & $\mathrm{C}_{25 \mathrm{a}}+\mathrm{C}_{25 \mathrm{~b}}$ & $\mathrm{~A}$ & $\mathrm{~B}$ & $\mathrm{~B} 2$ & $\mathrm{~B} 3+\mathrm{B} 4$ & $\mathrm{C}$ & $\mathrm{C} 1$ & & \\
\hline $\mathrm{ScM} 1$ & 1 & 2 & 50 & 23 & 10 & 5 & 4 & 5 & 1.3 & $97 \mathrm{~A}$ \\
$\mathrm{ScM} 2$ & 1 & 3 & 37 & 26 & 13 & 6 & 5 & 8 & 0.8 & $98 \mathrm{~S}$ \\
$\mathrm{ScM} 3$ & 1 & 2 & 54 & 16 & 9 & 4 & 5 & 8 & 1.8 & $67 \mathrm{~S}$ \\
$\mathrm{ScM} 4$ & 1 & 2 & 37 & 31 & 12 & 5 & 5 & 8 & 0.8 & $82 \mathrm{~A}$ \\
MSIM1 & - & 2 & 39 & 33 & 12 & 5 & 4 & 6 & 0.8 & $86 \mathrm{~A}$ \\
MSIM2 & 49 & 41 & 7 & - & 3 & - & - & - & - & $68 \mathrm{~A}$ \\
$\mathrm{CM}$ & 1 & 2 & 50 & 24 & 8 & 4 & 5 & 7 & 1.4 & $100 \mathrm{~A}$ \\
\hline
\end{tabular}

[a] Samples are described in the Supporting Information. [b] Defined as the ratio between the sum of all $\mathrm{C}_{26}$ and all $\mathrm{C}_{27}$ compound percentages.

The first striking observation is that all the mauveine salts that were synthesised and purified by Perkin are actually complex mixtures of at least thirteen different compounds, all of which contain the 7-amino-5-phenyl-3-(phenylamino)phenazin-5-ium core (Scheme 1). Besides the $\mathrm{C}_{24}$ compound with no methyl groups (pseudo-mauveine), two monomethylated $\mathrm{C}_{25}$ isomers, named $\mathrm{C}_{25 \mathrm{a}}$ and $\mathrm{C}_{25 \mathrm{~b}}$, dimethylated mauveine $A\left(C_{26}\right)$, four trimethylated mauveines $(B, B 2, B 3$, $\mathrm{B} 4)$, two tetramethylated mauveines $(\mathrm{C}, \mathrm{C} 1)$, one pentamethylated (D) and one hexamethylated (E) mauveines could be identified in the historical samples (see Table $\mathrm{S} 1$ in the Supporting Information). These last two compounds show that the commercial aniline used by Perkin was contaminated not only with toluidines but also with anilines containing two methyl groups in the benzene ring (xylidine). All these compounds have absorption wavelength maxima $\left(\lambda_{\max }\right)$ in methanol solution in the range $540-550 \mathrm{~nm}$, which is in agreement with previously reported results. ${ }^{[17]}$

Although the distribution of the mauveine compounds amongst the salt samples (Table 1) shows rather large dissimilarities, the two major chromophores present are (with the exception of Schunck's sample) mauveines $A\left(C_{26}\right)$ and $\mathrm{B}\left(\mathrm{C}_{27}\right)$. Other $\mathrm{C}_{27}$ isomers (mauveines $\mathrm{B} 3$ and $\mathrm{B} 4$ ), as well as $\mathrm{C}_{28}$ compounds (mauveines $\mathrm{C}$ and $\mathrm{C} 1$ ), are also present, with mauveine $\mathrm{B} 2$ as the most important of these minor compounds contributing approximately $10 \%$ to the overall colour. In three of these samples (ScM1 and 3, CM1; ScM= Science Museum, $\mathrm{CM}=$ Chandler Museum) mauveine $\mathrm{A}$ is present in a larger amount and contributes approximately $50 \%$ of the overall chromophores. On the other hand, when the $\mathrm{C}_{26} / \mathrm{C}_{27}$ ratio (Table 1) is considered in the other three samples (ScM2, 4 and MSIM1; MSIM= Museum of Science and Industry Manchester) the major chromophores are the $\mathrm{C}_{27}$ isomers, which throws some light on Perkin's flip-flop between a $\mathrm{C}_{26}$ or $\mathrm{C}_{27}$ formula for mauveine.

It is also worth noting that the so-called "original" Science Museum sample (ScM1) and the Chandler Museum sample (CM) are identical, but differ in one aspect or another from every other crystalline sample (Table 1). This could support the following hypothesis: both samples were from the batch made for the 1906 celebrations in France, which was made by using a recipe given by Perkin, but presumably with a mixture of pure aniline and toluidines rather than impure amines; Perkin would have taken this batch with him during his visit to New York to celebrate the Jubilee of mauveine and offered it to Charles Chandler.

In the sample that belonged to Schunk's (MSIM2) collection, a very different fingerprint was found. The major purple chromophore present was the $\mathrm{C}_{24}$ pseudo-mauveine $(49 \%)$ together with two mono-methylated derivatives $\left(\mathrm{C}_{25 \mathrm{a}}\right.$ and $\left.\mathrm{C}_{25 \mathrm{~b}}(41 \%)\right)$. There was also a minor component of mauveine A (7\%) and no evidence of mauveine B (nor C). This "outsider" sample could correspond to a different process than the one that Perkin developed for the production of mauveine; one that was moreover based on Perkin's observation that "pseudo-mauveine is obtained in the largest quantities when aniline of a low boiling point is used (aniline with low amounts of toluidine)" or in an unpublished synthetic procedure.

Counterions: The major counterions determined by ion-exchange chromatography, in five of the investigated seven samples, were acetate ions, thus confirming that these samples would have been prepared after 1862, and were to be used for dyeing and sent to the market in the form of "crystallised aniline purple" ${ }^{[8]}$ (Table 1). Acetate ion was found in two of these samples (ScM1 and CM) at approximately $100 \%$ and in the other four samples together with other ions, such as sulfate and chloride (see Figure S6 and Tables S7 and S8 in the Supporting Information). Sulfate was the major counterion found in the two samples, ScM2 and ScM3. The sulfate salt is described by Perkin as the product used to first precipitate the colouring matter from solution. The mauveine sulfate thus obtained could be then transformed in other salts.

We are led to conclude that the presence of acetate, as already mentioned by Morris, ${ }^{[18]}$ shows that these samples cannot be earlier than 1862 , as there is no historical evidence for the earlier synthesis of any salts as reasonably pure samples.

\section{Analysis of Perkin's mauve in textile samples}

Chromophores: Mauve-dyed textiles were also investigated because they constitute the most valuable available samples in terms of provenance and dating. These include the pieces donated by Miss A. F. Perkin, daughter of W. H. Perkin, in 
1947 to the Science Museum in London, ${ }^{[18]}$ which were a silk skein, a woollen shawl and a piece taken from a length of fabric (allegedly offered to Queen Victoria and possibly dyed immediately after the discovery of mauve; Figure 2). These samples might well date from 1857-60, and in the case of the skein and dress fabric possibly even as early as 1856. The dress fabric preserved at Perth also has a similar significance.

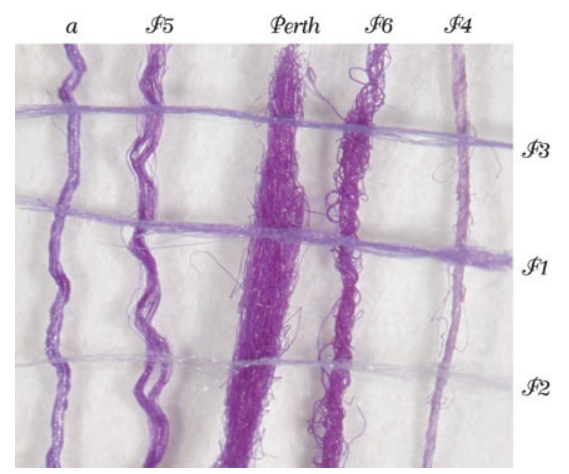

Figure 2. Textile samples from museum collections analysed in this work. The designations are in accordance with those given in Table 2. Fibre $a$ is a fibre that was dyed by us with mauveine ScM1, by using an original dyeing procedure described by Perkin. ${ }^{[1]}$ The $f$ fibers are all Science Museum (ScM) specimens.

After extraction of the dyes from the textiles (see Figures S1-S5 in the Supporting Information), the methanolic solutions were analysed as described above for the mauveine salts. The extraction procedure enabled a complete recovery of the mauveine chromophores, and thus their chemical fingerprint; this may be assumed because we know that the dye was almost completely taken up by the silk or wool fibres. ${ }^{[1] 6}$

In the analyses of the textile fibres, evidence for two different processes seems clear, see Table 2, and consequently the six studied samples can be grouped in two sets of respectively four and three samples. 1) In the first sample, the major chromophores are mauveines $\mathrm{A}$ and $\mathrm{B}$, with the mono-methyl derivatives $\mathrm{C}_{25}$ present in minor amounts (1$5 \%)$ and no pseudo-mauveine is detected. 2) In the second sample, the major chromophore is mauveine A (ca. 50\%) together with mono-methyl derivative isomers $\mathrm{C}_{25 \mathrm{a}+\mathrm{b}}(15-$ $20 \%$ ); pseudo-mauveine is also present (ca. 5\%) together with mauveine B (5-12\%).

The dye composition in the fibres, particularly for set number 2 , is consistent and consequently might reflect the standard procedures for the production of mauve. In this second set, we find samples that were most probably dyed by professional dyers.

From the above, it is possible to conclude that the process used to dye the first dated fabrics, set number 2, was based

\footnotetext{
${ }^{6}$ Quote from Perkin (see reference [1], p. 250): "Many of them, as aniline-purple and violine, are taken from their aqueous solution so perfectly by these substances, that the water in which they were dissolved is left colourless."
}

Table 2. Relative percentages of the main chromophores of the mauveine-dyed textile samples.

\begin{tabular}{llllllllll}
\hline & $\mathrm{C}_{24}$ & $\mathrm{C}_{25}$ & $\mathrm{C}_{26}$ & $\mathrm{C}_{27}$ & $\mathrm{C}_{27}$ & $\mathrm{C}_{27}$ & $\mathrm{C}_{28}$ & $\mathrm{C}_{28}$ & $\mathrm{C}_{26} / \mathrm{C}_{27}{ }^{[\mathrm{a}]}$ \\
& & $\mathrm{C}_{25 \mathrm{a}}+\mathrm{C}_{25 \mathrm{~b}}$ & $\mathrm{~A}$ & $\mathrm{~B}$ & $\mathrm{~B} 2$ & $\mathrm{~B} 3+\mathrm{B} 4$ & $\mathrm{C}$ & $\mathrm{C} 1$ & \\
\hline ScMF1 & - & 1 & 32 & 36 & 11 & 4 & 7 & 9 & 0.6 \\
ScMF2 $^{[\mathrm{b}]}$ & - & 5 & 70 & 13 & 7 & 4 & 1 & & 3.0 \\
ScMF3 & - & 2 & 61 & 21 & 8 & 5 & 2 & 2 & 1.8 \\
ScMF4 & - & 2 & 53 & 24 & 9 & 5 & 3 & 4 & 1.4 \\
& & & & & & & & & \\
ScMF5 & 5 & 20 & 51 & 5 & 11 & 9 & - & - & 2.1 \\
Perth & 4 & 18 & 50 & 12 & 9 & 7 & - & - & 1.8 \\
ScMF6 & 5 & 15 & 51 & 11 & 11 & 7 & - & - & 1.7
\end{tabular}

[a] The structural assignment of these three (mauveine B3, B4 and C1) structures was not made. However, based on the available analytical data these could be clearly identified as isomers of mauveines B and C; see Table S1 in the Supporting Information.[a] The concentration of mauve in this sample was very low; see Figure S5 in the Supporting Information.

on the method described by Perkin as enabling to obtain "a blue shade of mauve prepared from aniline, containing but little toluidine". ${ }^{[10]}$ This would correspond to the first largescale product introduced in the market, in which "commercial mauve appeared as an almost perfectly amorphous body". ${ }^{[19]}$ Only in a second period, "owing to the great improvements which have been made in its purification" ${ }^{[19]}$ was it sent "into the market pure and crystallized". ${ }^{[19]}$ This is also in agreement with what Perkin wrote in his 1879 paper, namely, that to obtain the mauveine acetate in the form of a crystallised product, it was necessary to have a mauve dye enriched in methylated derivatives. ${ }^{[10] 7}$ This could potentially explain the differences observed between several of the investigated mauve-dyed textiles: the skeins from the first group correspond to a later process, when the dye was sold as a crystallised acetate salt. Included in the second group should be the textiles that would have been dyed by the original process, when mauve was sold as an "amorphous body" (or as a solution), including the only dated sample, the beautiful mauve-dyed woollen shawl (see ScMF6 in Figure 1).

The mauve used in the woollen scarf (ScMF6) and the Perth silk fabric, allegedly from a textile dyed for Queen Victoria, is very similar in composition. This indicates that they were both very early and in the case of the Perth sample, and given what is known of the history, it can probably be dated to 1856 . The Science Museum silk sample (ScMF5) is also similar in appearance to the Perth sample and although it agrees in general terms with the other two samples, it does differ in respect of one isomer $\left(\mathrm{C}_{27}\right.$, mauveine B). However it is unlikely that this difference is significant, and consequently all three samples should be considered to be examples of the earlier synthetic mauveine period.

\footnotetext{
${ }^{7}$ Quote from Perkin (see reference [10], pp. 717-718): "When manufacturing this product, it was always found best to use colouring matter made from aniline containing large quantities of toluidine, otherwise the crop of crystals was very small, most of the colouring matter remaining in solution."
} 
Metal ions used as mordants: The use of mordants was an issue that was addressed by Perkin because they were critical for the dyeing of cotton, although mauve is a basic dye for silk with no need of mordant. ${ }^{[1]} \mathrm{A}$ mordant is a metallic ion that binds simultaneously to the fibre and to the dye. ${ }^{[20,21]}$ It can also play an important role in the final colour obtained. Alum, a source of the aluminium ion was an important historical mordant, but it did not work for binding mauve to cotton. Tannins were used to improve the binding of the chromophores to the textile. Methods to fix mauve to cotton had to be researched by Perkin himself and by professional dyers, such as the Pullar family of Perth. The optimised recipe involved the use of tannins and tin. ${ }^{[1]}$

Three textile samples with different fibres, cotton (ScMF4), wool (ScMF6) and silk (Perth Museum) were analysed for the presence of aluminium, tin and iron by using ICP-AES (see Table S9 in the Supporting Information). The results obtained were in agreement with what was to be expected from Perkin's papers; silk was not mordanted, and no metal ions were necessary to dye silk with mauve. In wool, aluminium and iron were detected at 5.9 and $5.6 \mathrm{mg}$ per gram of textile, respectively. The amounts of aluminium and iron ions are in the concentration range of mordanted wool textiles. ${ }^{[20]}$ In his patent, Perkin mentioned that he found it advantageous to boil the wool with the mauve dye and sulfate of iron. But, Perkin also claimed that Prussian Blue was used to give a bluer shade to mauve-dyed textiles. ${ }^{[10]}$ So the presence of iron could be explained by its use as a mordant in wool or/and by its use as Prussian blue. ScMF4 displays tin as mordant, as predicted, because in 1857 Perkin and Pullars started using tin to fix mauve (then known as Tyrian purple) onto cellulose-based textiles. With this method, the mauveine dye would withstand the action of soap. ${ }^{[1]}$

\section{Conclusion}

Two sets of historical samples were analysed: seven mauve salts and seven dyed textiles. The only dated sample in this set is a mauve-dyed shawl exhibited at the 1862 London International Exhibition. Two $\mathrm{C}_{25}$ compounds were described and characterised for the first time in historic mauve samples. With the exception of the mauve salt from the Schunk collection, all contained a common fingerprint in which mauveine A or B (and isomers) predominate. Besides these two and three methyl derivatives of pseudo-mauveine, several other methylated derivatives were found (mono, tetra and more). Amongst these, mauveine B2 $\left(\mathrm{C}_{27}\right)$ and mauveines $\mathrm{C}_{25 \mathrm{a}+\mathrm{b}}$ are important markers in the fingerprint of mauveine salts and textiles, respectively. Pseudo-mauveine, which was described by Perkin as a second colouring matter in the mauve dye, was also identified for the first time in historical samples.

Mauve is a complex mixture of methyl derivatives of 7amino-5-phenyl-3-(phenylamino)phenazin-5-ium. By investigating mauveine samples and fabric tests dyed with mauveine from different sources, we were able to understand the evolution of mauve as a commercial dye. In the first commercial product, mauveine $\mathrm{A}$ is the major chromophore $(50 \%)$ followed by mauveines $\mathrm{C}_{25}(15-20 \%)$. Later, Perkin changed the process to obtain more soluble mauve with acetate as the counterion. In this second process, a higher concentration of toluidine was used as a starting material, which led to higher percentages of mauveine B. We found this fingerprint in several salt samples. In the majority of these samples, acetate was found as the major counterion, which confirms that all the mauve salts were made with the second process and should be dated after 1862 . The only exception to the general fingerprint (mauveine A or B as major chromophores) is the sample from Schunk's collection (MSIM2), in which pseudo-mauveine and monomethyl mauveines $C_{25}$ predominate; this reflects a different and possibly later process for the synthesis of mauve after it had ceased to be used as a commercial dye.

Mauve is now a chemical icon. Before achieving this status mauve was a commercial dye that achieved great success as a fashionable colour between 1858 and 1863. From Perkin's articles we know that mauve dyed silk very easily, so efficiently indeed that no mordant was necessary to bind the colouring matter to the textile. This was confirmed in the present study. It was also possible to completely extract the dye, enabling us to reconstitute the original chromophore fingerprint. With this in mind, it was possible to conclude that mauve was made according to the original recipe in three of the textile samples. These textiles, the shawl (exhibited in the 1862 International Exhibition) and two fabrics that were dyed by the Pullar family of Perth (Scotland) can be considered to be the iconic representatives of the initial mauve mania.

\section{Experimental Section}

Origin of the different samples: The samples studied in this work were obtained from the Science Museum in London, Chandler Museum in New York, Museum of Science and Industry in Manchester and Perth Museum in Scotland. Two kinds of samples were analysed: seven mauveine salts and seven textile samples dyed with mauve.

Mauve salt samples: ScM1 sample came from Imperial College, and is now displayed in the Science Museum with a label which reads "Original Mauveine Prepared By Sir William Henry Perkin in 1856". The samples ScM2, 3 and 4 were donated to the Science Museum by Miss A.F. Perkin, daughter of W. H. Perkin, in 1947. The MSIM1 sample was given by the Kirkpatrick branch of the Perkin family to ICI and was subsequently transferred to the Museum of Science and Industry. MSIM2 was a sample of mauveine from the Schunck collection and was labelled "mauveine C27 H24 N4". The handwriting looks like other samples in the collections and was probably written by Schunck or his assistant. The CM1 sample is a specimen from the Chandler Museum at Columbia University, New York City and was given to Prof. C. Chandler by W. H. Perkin during his visit to New York in October 1906.

Textile samples: Samples from seven different textiles were analysed. The ScMF1, F2, F3 and F4 samples were donated by Miss A. F. Perkin to the Science Museum in 1947 and were possibly made for the 1862 international exhibition. ScMF1 to F3 were mauve silk skeins and F4 is a cotton skein; F1 is a dark mauve and F2 is a pale mauve. Both ScMF5 and F6 were samples from fabrics. ScMF5 is from a small piece of silk fabric dyed with mauveine of a pattern that was allegedly supplied to Queen 
Victoria about 1860. ScMF6 comes from a mauve-dyed shawl that was about 2 yards square, which was exhibited at the International Exhibition of 1862 . It was the only sample that could be accurately dated as having been dyed before 1862 .

The sample from the Perth Museum Scotland (Perth) comes from a fabric given by the Pullar family in 1938 to the Perth and in the register notes, it was written that this sample was "cut from the first length of material dyed by Dr Perkins [sic] by his new process in Pullar's works, Perth in 1856 ".

Sample characterisation: All the mauve salt samples were dissolved in methanol. The chromophores in the textiles were isolated by using three different soft extraction methods. HPLC-DAD and HPLC-MS were used to analyse and isolate the compounds (salt samples and fabrics) that were then characterised by ${ }^{1} \mathrm{H}$ and ${ }^{13} \mathrm{C}$ NMR spectroscopy and mass spectrometry (FD-MS and FTICR-MS).

The distribution of the several mauveine chromophores was quantified as follows. The HPLC-DAD chromatograms of mauveine were acquired at $550 \mathrm{~nm}$ (see Figure S1 in the Supporting Information). The peak areas of the chromophores were obtained with the chromatographic program ChromQuest 4.1. These areas were then corrected for the different molar absorptivity of each compound and are presented in Table 1 (dividing by the correcting factors, see below). The following molar absorptivites were determined: $\left(\varepsilon / \mathrm{M}^{-1} \mathrm{~cm}^{-1}\right)$ mauveine $\mathrm{A}=22000$, mauveine $\mathrm{B}=29000$, mauveine $\mathrm{B} 2=33000$, and mauveine $\mathrm{C}=36500$; these gave rise to the following correcting factors: mauveine $\mathrm{A}=0.6$, mauveine $\mathrm{B}=0.8$, mauveine $\mathrm{B} 2=0.9$ (value also used for mauveines $\mathrm{B} 3$ and $\mathrm{B} 4$ ); mauveine $\mathrm{C}=1$ (value also used for mauveine $\mathrm{C} 1$ ). For a detailed description, see Supporting Information, sections Data Summary, HPLC-DAD/LC-MS characterization of historical maveines samples, and NMR characterization of the compounds isolated by HPLC

The counterions of salt samples were identified by using HPLC anion exchange chromatography (see for details see Figure S5 (counterion analysis) in the Supporting Information). The textiles were analysed for the presence of aluminium, iron and tin that might have been used as mordants by ICP-AES, see mordent analysis in the Supporting Information.

\section{Apparatus}

HPLC: The dye analyses were performed in an analytical Thermofinnigan Surveyor HPLC-DAD system with a PDA 5 by using a RP-18 analytic column $(250 \times 4.6$ Nucleosil $300-5 \mathrm{C} 18)$. A solvent gradient with $\mathrm{MeOH}$ (A), $0.05 \mathrm{M} \mathrm{CH}_{3} \mathrm{CO}_{2} \mathrm{NH}_{4}$ (B), acetonitrile (C) with a flow rate of $1.7 \mathrm{~mL} \mathrm{~min}^{-1}$ for the chromophores separation was developed: $0-2 \mathrm{~min}$ : $20 \% \mathrm{~A} / 50 \% \mathrm{~B} / 30 \% \mathrm{C}$, isocratic; $10 \mathrm{~min}: 25 \% \mathrm{~A} / 35 \% \mathrm{~B} / 40 \% \mathrm{C}$ linear; 20 min: $40 \% \mathrm{~A} / 20 \% \mathrm{~B} / 40 \% \mathrm{C}$ linear; $25 \mathrm{~min}$ : $50 \% \mathrm{~A} / 50 \%$ C linear; $25-$ $30 \min : 50 \% \mathrm{~A} / 50 \% \mathrm{C}$ isocratic.

The analysis of ScMF6, F1 and MSIM2 samples were also performed on a HPLC-MS instrument with a ProStar 410 autosampler, two 212-LC chromatography pumps, a ProStar 335 diode array detector and a 500MS ion-trap mass spectrometer with an ES ion source (Varian, Inc., Palo Alto, CA, USA). The LC separations were carried out by using a Polaris C18 A, with $5 \mathrm{~mm}$ of particle size $(150 \times 2 \mathrm{~mm})$. The mobile phase was composed by $\mathrm{MeOH}(\mathrm{A})$ and $0.08 \%(\mathrm{v} / \mathrm{v})$ formic acid (aq.) (B). The following gradient was used at a flow rate of $0.03 \mathrm{mLmin}^{-1}: 0-2 \mathrm{~min}: 50 \%$ $\mathrm{A} / 50 \% \mathrm{~B}$ isocratic; $10 \mathrm{~min}$ : $60 \% \mathrm{~A} / 40 \%$ Blinear; $20 \mathrm{~min}: 75 \% \mathrm{~A} / 25 \% \mathrm{~B}$ linear; 30-35 min: 100\% A isocratic.

The isolation of major compounds of mauve dye was performed in a semipreparative 6000 Merck Hitachi HPLC-DAD system with a L-6200 A Intelligent Pump, a L-5025 Column Thermostat and a L-4500 DAD. The separations were carried out by using a RP-18 semipreparative column $(250 \times 10$ Nucleosil $300-7 \mathrm{C} 18)$, by using the acidic $\mathrm{H}_{2} \mathrm{O}$ and $\mathrm{MeOH}$ method described elsewhere. ${ }^{[16]}$

Mass spectrometry: The mass spectra carried out in the 500-MS ion-trap mass spectrometer with an ES ion source (Varian, Palo Alto, CA, USA) were acquired in positive-ion mode The operating parameters were optimised for the sample ScMF1: the spray needle voltage was set at $\pm 5.7 \mathrm{kV}$, nitrogen was used both as nebulising and drying gas (35 psi and $15 \mathrm{psi}$, respectively), drying gas temperature $350^{\circ} \mathrm{C}$; capillary voltage $157 \mathrm{~V}$ for positive ions, and RF loading of $94 \mathrm{~V}$.
Field-desorption mass spectra (FD-MS) were run on a Micromass GCTOF spectrometer in positive mode.

High-resolution mass spectra (HRMS) were obtained by laser desorption/ionization (LDI) with a Finnigan FT/MS 2001-DT Fourier-transform ion-cyclotron-resonance mass spectrometer (FTICR/MS), equipped with a 3 Tesla superconducting magnet and coupled to a Spectra-Physics Quanta-Ray GCR-11 Nd:YAG laser operated at the fundamental wavelength $(1064 \mathrm{~nm})$.

NMR spectroscopy: The NMR spectra at $298.0 \mathrm{~K}$ were obtained either on a Bruker AMX400 operating at $400.13 \mathrm{MHz}\left({ }^{1} \mathrm{H}\right)$ and $100 \mathrm{MHz}\left({ }^{13} \mathrm{C}\right)$ or on a Bruker Avance 600 operating at $600.13 \mathrm{~Hz}\left({ }^{1} \mathrm{H}\right)$ and $150.91 \mathrm{~Hz}$ $\left({ }^{13} \mathrm{C}\right)$. For each compound, ${ }^{1} \mathrm{H},{ }^{13} \mathrm{C}$, COSY, HSQC or HMQC, HMBC and eventually NOESY NMR spectra were run. Proton assignment was done on the basis of chemical shifts and COSY spectra; to confirm these assignments, NOESY spectra were run on one of the samples (pseudomauveine; mixing times of $0.5,1.0$ and $1.5 \mathrm{~s}$ were used, and the best spectrum selected), to fully confirm the assignments. Carbon assignments were made on the basis of chemical shifts, HSQC or HMQC, and HMBC NMR spectra. For more details see Supporting Information.

\section{Acknowledgements}

We are grateful to POCI (POCI/QUI/55672/2004 and PTDC/EAT/65445/ 2006), FCT and FEDER for further funding. We also acknowledge Perth Museum (Scotland), Museum of Science and Industry in Manchester, Columbia University, New York City, and the Science Museum, London, for the samples, A. Travis for comments and to J. Marçalo (ITN) and M. da Conceição (IST) Oliveira for help with MS measurements.

[1] W. H. Perkin, J. Chem. Soc. 1862, 14, 230-255.

[2] A. S. Travis, The Rainbow Makers: The Origins of the Synthetic Dyestuffs Industry in Western Europe, Bethlehem, Lehigh University Press, 1993.

[3] P. Ball, Bright Earth: Art and the Invention of Color, Farrar, Straus and Giroux, New York, 2002.

[4] S. Garfield, Mauve: How One Man Invented a Color That Changed the World, W. W. Norton, 2002.

[5] P. Ball, Nature 2006, 440, 429-429.

[6] A. S. Travis, Hist. Technol. 2006, 22, 131-152.

[7] W. H. Perkin, Science 1906, 24, 488-493.

[8] W. H. Perkin, J. Chem. Soc. Trans. 1896, 596-637.

[9] I. Holme, Color. Technol. 2006, 122, 235-251.

[10] W. H. Perkin, J. Chem. Soc. Trans. 1879, 717-732.

[11] O. Meth-Cohn, M. Smith, J. Chem. Soc., Perkin Trans. 1 1994, 5-7.

[12] O. Fischer, E. Hepp, Chem. Ber.1893, 26, 1194-1196.

[13] R. Nietzki, Chem. Ber.1896, 29, 1442-1446.

[14] A. Cobenzl, Oesterr. Chem. -Ztg. 1925, 28, 25-28.

[15] E. Gurr, J. Soc. Dyers Colour. 1969, 85, 473-474.

[16] J. Seixas de Melo, S. Takato, M. Sousa, M. J. Melo, A. J. Parola, Chem. Commun. 2007, 2624-2626.

[17] M. R. van Bommel, I. V. Berghe, A. M. Wallert, R. Boitelle, J. Wouters, J. Chromatog. A 2007, 1157, 260-272.

[18] P. J. T. Morris, Hist. Technol. 2006, 22, 119-130.

[19] W. H. Perkin, Proc. R. Soc. London Ser. A 1862/63, 13, 170-176.

[20] M. Sousa, M. J. Melo, A. Aguiar-Ricardo, P. Cruz in A Green Approach to Antique Textile Cleaning, Vol. II (Ed.: James \& James), International Council of Museums Committee for Conservation, The Hague, 2005, pp. 944-953.

[21] C. Dominique, Natural Dyes: Sources, Tradition, Technology and Science, Archetype Publications, London 2007.

[22] O. Meth-Cohn, A. S. Travis, Chem. Brit. 1995, 31, 547-549.

[23] D. A. Rosenstiehl, Bull. Soc. Ind. Mulhouse 1869, 39, 201.

Received: April 15, 2008 Published online: August 1, 2008 